Care: Jurnal Ilmiah Ilmu Kesehatan Vol .7, No.2, 2019, hal 54-60

Tersedia online di https://jurnal.unitri.ac.id/index.php/care

ISSN 2527-8487 (online)

ISSN 2089-4503 (cetak)

\title{
PERBEDAAN DISFUNGSI SEKSUAL PADA WANITA PASCA PERSALINAN PERVAGINAM EPISIOTOMI MEDIOLATERAL DAN SEKSIO CAESARIA
}

\author{
Roni Subrata ${ }^{1)}$, Retno Rahayu ${ }^{2)}$ \\ ${ }^{1), 2)}$ Program Studi Diploma 3 Akademi Kebidanan Wira Husada Nusantara Malang \\ E-mail:r.ronisubrata@gmail.com
}

\begin{abstract}
Postpartum women will experience some changes related to the labor process experienced. Changes that occur are the presence of physical and psychological discomfort. These changes can affect the sexual needs of women and their partners. Causes of Postpartum Female Sexual Dysfunction are dyspareunia, perineal pain, incision wound discomfort including surgery, reduced libido, lack of lubrication in the vagina, changes in body image to negative and anorgasms associated with pain and trauma. The purpose of this study was to determine the differences in sexual dysfunction of women after vaginal delivery with a mediolateral episiotomy with cesarean section at Bangil Pasuruan Hospital. This research using a cross sectional method. The study subjects consisted of vaginal delivery women with mediolateral episiotomy and post cesarean section. Each group consists of 30 people. The sampling technique used was consecutive sampling. After three months postpartum, sexual function is assessed using an FSFI score (Femal Sexual Function Index. Data in the form of a questionnaire then tested by analysis of the T-test. The results of this study a difference between postpartum female sexual dysfunction and mediolateral episiotomy with cesarean section, seen from the desirability of 4,787> 1.67, stimulation 8.723> 1.67 lubrication namely 9,102>1.67 orgasm namely 7,381>1.67 satisfaction is $11,040>1,67$ and pain 9,981>1,67.
\end{abstract}

Keywords : Sexual Disfunction; Mediolateral Episiotomy; Sesarea Section; FSFI Score.

\begin{abstract}
ABSTRAK
Perempuan pasca salin akan mengalami perubahan berkaitan dengan proses persalinan yang dialami. Perubahan yang terjadi adalah adanya ketidaknyamanan fisik dan psikologis. Perubahan itu dapat mempengaruhi kebutuhan seksualitas baik pada perempuan maupun pada pasangan. Penyebab dari Postpartum Female Sexual Dysfunction secara umum adalah dispareunia, nyeri perineal, ketidaknyamanan luka insisi berkurangnya libido, berkurangnya lubrikasi pada vagina, perubahan citra tubuh menjadi negatif serta anorgasme yang dihubungkan dengan nyeri dan trauma. Tujuan dari penelitian ini adalah mengetahui perbedaan disfungsi seksual wanita pasca persalinan pervaginam dengan episiotomi mediolateral dengan seksio sesarea di Rumah Sakit Bangil Pasuruan. Metode penelitian ini adalah cross sectional. Subjek penelitian ini adalah wanita paca persalinan pervaginam dengan episiotomi mediolateral dan persalinan seksio sesarea. Masing-masing kelompok terdiri dari 30 orang. Teknik sampling yang digunkan adalah consecutive sampling. Setelah 3 bulan pasca persalinan, dilakukan penilaian fungsi seksual

Cara mengutip: Subrata, Roni \& Rahayu, Retno. (2019). Perbedaan Disfungsi Seksual antara Perempuan Pasca Persalinan Pervaginam dengan Episiotomi Mediolateral dan Seksio Caesaria. Care:Jurnal Ilmiah Ilmu Kesehatan, 7(2), 54-60


menggunakan skor FSFI (Femal Sexual Function Index). Data yang berupa kuesioner selanjutnya diuji dengan analisis Uji T-test. Hasil penelitian ini menunjukkan ada perbedaan antara disfungsi seksual wanita pasca persalinan dengan episiotomi mediolateral dengan seksio sesarea, dilihat dari hasrat thitung 4,787 $>$ ttabel 1,67, rangsangan 8,723 $>1,67$ lubrikasi yaitu $9,102>1,67$ orgasme yaitu 7,381 $>1,67$ kepuasan yaitu 11,040 $>1,67$ dan nyeri 9,981 > 1,67.

Kata Kunci : Disfungsi Seksual; Episiotomi Mediolateral; Seksio Sesarea; Skor FSFI.

\section{PENDAHULUAN}

wanita pasca melahirkan akan mengalami perubahan berkaitan dengan proses persalinan yang dialami. Perubahan yang terjadi adalah adanya ketidaknyamanan fisik dan psikologis. Perubahan itu bisa mempengaruhi kebutuhan seksualitas baik pada perempuan maupun pasangan. Ketidaknyamanan fisik diantaranya mencakup kondisi kelelahan, kurang kuatnya fisik, ketidaknyamanan karena pembengkakan payudara, pengeluaran lochea dan adanya nyeri perineal.

Ketidaknyamanan psikologis antara lain adanya perasaan takut terhadap nyeri, perasaan cemas berlebihan terhadap bayi, merasa penampilan tidak memuaskan, berkurangnya privasi dan waktu dalam berhubungan intim. Ketidaknyamanan fisik dan psikologis bisa mempengaruhi keharmonisan hubungan dalam sebuah perkawinan (Breslin, \& Lucas, 2003).

Penyebab dari kejadian Postpartum Female Sexual Dysfunction (PPFSD) adalah dispareunia, nyeri perineal, ketidaknyamanan luka insisi termasuk di dalamnya tindakan pembedahan, berkurangnya libido, ber kurangnya lubrikasi pada vagina, perubahan citra tubuh menjadi negatif serta anorgasme. Hasil penelitian menunjukkan bahwa angka kejadian Postpartum Female Sexual Dysfunction pada 3 bulan pertama pasca persalinan adalah $70,6 \%$ menurun menjadi $55,6 \%$ pada 4 sampai 6 bulan dan berkurang menjadi $34,2 \%$ pada 6 bulan ke atas pasca melahirkan (Breslin, \& Lucas, 2003).

Penelitian (Trutnovsky, 2006) menyebutkan bahwa berdasarkan wawancara dengan perempuan pasca melahirkan, diperoleh hasil yang menyatakan bahwa mereka kembali aktif secara seksual rata-rata setelah 7 minggu. Pada 6 bulan pasca salin, 16 orang $(61 \%)$ mengalami peningkatan pada hubungan seksual, sedangkan 10 perempuan $(39 \%)$ merasakan tidak ada perbedaan.

Pada 6 bulan rata-rata hubungan seksual itu mengalami peningkatan, akan tetapi masih jauh lebih rendah dibandingkan dengan 
sebelum hamil. Sebaliknya, rata-rata kepuasan seksual jauh lebih menurun pada periode pasca melahirkan daripada masa di akhir kehamilan, dan hal itu lebih rendah jika dibandingkan dengan sebelum hamil.

Bila dibandingkan dengan persalinan pervaginam secara spontan, tampaknya logis apabila kita berasumsi bahwa wanita yang melahirkan secara seksio caesarea lebih kecil kemungkinannya untuk mengalami nyeri perineum, dibandingkan dengan persalinan dengan episiotomi ataupun dibantu ditindakan (Buhling, et al., 2006). Tetapi, persalinan dengan seksio sesarea sendiri bukannya tanpa bahaya, bahkan terhadap seksualitas itu sendiri.

Menurut Alexander (2006) hasil penelitian terkait disfungsi seksual pasca melahirkan, terdapat beberapa faktor yang dapat menghambat hubungan seksual pada perempuan pasca melahirkan yaitu: Kelelahan, Dispareunia, Depresi Pasca Melahirkan, Trauma Melahirkan, Riwayat Sebelum Hamil, Pengaruh Mode of Delivery pada Disfungsi Seksual. Tetapi secara umum, episiotomi ataupun seksio sesarea yang mengalami komplikasi akan berdampak buruk terhadap kehidupan seksual wanita pasca persalinan, baik secara fisik maupun psikis.
Meskipun bukan merupakan prosedur rutin, sebagian besar persalinan di pervaginam pada wanita primigravida di Rumah Sakit Bangil Pasuruan dilakukan episiotomi mediolateral. Sedangkan seksio sesarea non elektif tidak sedikit yang berdampak pada fungsi seksual pasca persalinan, baik oleh karena kehamilan, indikasi operasi, ataupun komplikasi yang ditimbulkannya. Tujuan dari penelitian adalah untuk mengetahui perbedaan disfungsi seksual wanita pasca persalinan pervaginam dengan episiotomi mediolateral dengan seksio sesarea di Rumah Sakit Bangil Pasuruan.

\section{METODE PENELITIAN}

Jenis penelitian ini adlahy penelitian kuantitatif dengan menggunakan studi potong lintang analitik (cross-sectional study). Lokasi penelitian adalah RS Bangil dan dilaksanakan padabulan Februari sampai Mei 2018 (tiga bulan pasca persalinan untuk sampel yang melahirkan di RS pada bulan Oktober tahun 2017 sampai bulan Januari 2018). Variabel penelitian ini terbagi menjadi variabel tergantung (fungsi seksual), variabel bebas (persalinan pervaginam dengan episiotomi dan persalinan dengan seksio sesarea) dan Populasi dalam penelitian ini adalah wanita pasca persalinan pervaginam dengan episiotomi dan pasca seksio sesarea yang melahirkan di RS Bangil pada Bulan Oktober 2017 sampai 
bulan Januari 2018.

Sampel penelitian ini adalah 30 orang sampel untuk kelompok episiotomi dan 30 orang sampel untuk kelompok seksio sesareayang sudah memenuhi kriteria inklusi dan eksklusi, setelah tiga bulan pasca persalinan. Data yang digunakan dalam penelitian merupakan data primer. Pengumpulan data primer dalam penelitian dilakukan melalui cara menyebarkan kuisioner dengan responden langsung. Kuisioner FSFI (Female Sexual Function Index) yang memuat tentang fungsi seksual digunakan sebagai indikator untuk variabel $\mathrm{X}$. Wanita pasca persalinan yang memenuhi kriteria inklusi dan eksklusi dipilih secara consecutive sampling masing masing 30 orang untuk tiap kelompok.

Selanjutnya pasien mengisi kuisioner dan peneliti menganamnesis dan penelusuran rekaman medik untuk melengkapi data . Apabila pasien mengalami kesulitan dalam membaca maka peneliti akan membantu untuk membacakan kuisioner FSFI (Female Sexual Function Index) yang sudah tersedia. sampel dikelompokkan menjadi 2 kelompok yaitu kelompok persalinan dengan episiotomi dan persalinan dengan seksio sesarea, dan selanjutnya dilakukan pengukuran fungsi seksual.
Setelah dilakukan evaluasi ulang terhadap kelengkapan data, dilakukan analisis dengan perangkat lunak komputer : a. Analisis statistik deskriptif pada data demografil. b. Penentuan skoring pada jawaban setiap pertanyaan dari kuisioner FSFI yang telah diisi responden lalu ditentukan jenis dan derajat disfungsi masing-masing subyek c. Perbedaan skor FSFI antara kelompok yang melahirkan pervaginam dengan episiotomi dan kelompok persalinan seksio sesarea untuk menguji perbedaan fungsi seksual digunakan uji $t$ test tidak berpasangan. d. Analisis statistik menggunakan interval kepercayaan (IK) 95\%. Hubungan dikatakansignifikan apabila nilai dari $\mathrm{p}<$ 0,05 .

\section{HASIL}

Berdasarkan Tabel 1 terlihat bahwa nilai rata -rata untuk variabel hasrat, rangsangan, lubrikasi, orgasme, kepuasan, nyeri pada persalinan pervaginam dengan episiotomi nilainya lebih tinggi dibandingkan dengan persalinan dengan seksio caesaria. Dari seluruh variabel yang tertinggi adalah lubrikasi dari sini memiliki makna bahwa persalinan pervaginam dengan episiotomi untuk lubrikasi saat hubungan seksual nialinya lebih tinggi dengan nilai rata - rata $15.17 \pm 2.960$ 
Tabel 1. Nilai rata-rata dan standar devisi variabel penelitian pada persalinan pervaginam dengan episiotomi dan persalinan dengan seksio sesarea

\begin{tabular}{lllll}
\hline Variabel & Rata -rata & \multicolumn{3}{l}{ SD } \\
\cline { 2 - 5 } Hasrat & Episiotomi & SC & Episiotomi & SC \\
Rangsangan & 4.60 & 3.00 & 1.589 & 0.910 \\
Lubrikasi & 11.17 & 4.13 & 3.141 & 3.104 \\
Orgasme & 15.17 & 4.40 & 2.960 & 5.763 \\
Kepuasan & 8.43 & 2.77 & 2.029 & 3.683 \\
Nyeri & 11.37 & 4.70 & 2.059 & 2.588 \\
\hline
\end{tabular}

Berdasarkan Tabel 2 nilai $t_{\text {hitung }}$ hasrat (desire) lebih besar dari pada $t_{\text {tabel }}$ yaitu $t_{\text {hitung }} 4,787>$ $\mathrm{t}_{\text {tabel }} 1,67$ yang artinya ada perbedaaan yang signifikan antara persalinan normal dengan episiotomi denganpersalinan sectio cesarea dengan nilai signifikansi 0,00 . Nilai $t_{\text {hitung }}$ rangsangan (arousal) lebih besar dari pada $t_{\text {tabel }}$ yaitu $t_{\text {hitung }} 8,723>t_{\text {tabel }} 1,67$ yang artinya ada perbedaaan yang signifikan antara persalinan normal dengan episiotomi denganpersalinan sectio cesarea dengan nilai signifikansi 0,00 . Nilai $t_{\text {hitung }}$ lubrikasi (lubrication) lebih besar dari pada $\mathrm{t}_{\text {tabel }}$ yaitu $t_{\text {hitung }} 9,102>t_{\text {tabel }} 1,67$ yang artinya ada perbedaaan yang signifikan antara persalinan normal dengan episiotomi denganpersalinan sectio cesarea dengan nilai signifikansi 0,00 . Nilai $t_{\text {hitung }}$ Orgasme (orgasm) lebih besar dari pada $t_{\text {tabel }}$ yaitu $t_{\text {hitung }}$ $7,381>t_{\text {tabel }} 1,67$ yang artinya ada perbedaaan yang signifikan antara persalinan normal dengan episiotomi dengan persalinan sectio cesarea dengan nilai signifikansi 0,00 . Nilai $t_{\text {hitung }}$ kepuasan (satisfaction) lebih besar dari pada $t_{\text {tabel }}$ yaitu $\mathrm{t}_{\text {hitung }} 11,040>\mathrm{t}_{\text {tabel }}$ 1,67 yang artinya ada perbedaaan yang signifikan antara persalinan normal dengan episiotomi denganpersalinan sectio cesarea dengan nilai signifikansi 0,00 . Nilai $t_{\text {hitung }}$ nyeri (pain) lebih besar dari pada $t_{\text {tabel }}$ yaitu $t_{\text {hitung }}$ 9,981 > $\mathrm{t}_{\text {tabel }}$ 1,67 yang artinya ada perbedaaan yang signifikan antara persalinan normal dengan episiotomi denganpersalinan sectio cesarea dengan nilai signifikansi 0,00 .

Tabel 2. Nilai $t_{\text {hitung }}$ pada persalinan pervaginam dengan episiotomi dan persalinan dengan seksio sesarea

\begin{tabular}{lccc}
\hline Variabel & $\mathbf{N}$ & $\mathbf{t}_{\text {hitung }}$ & Variabel \\
\hline Hasrat & 30 & 4,787 & hasrat \\
Rangsangan & 30 & 8,723 & Rangsangan \\
Lubrikasi & 30 & 9,102 & Lubrikasi \\
Orgasme & 30 & 7,381 & Orgasme \\
Kepuasan & 30 & 11,040 & Kepuasan \\
Nyeri & 30 & 9,981 & Nyeri \\
\hline
\end{tabular}




\section{PEMBAHASAN}

Dari hasil diatas menunjukkan bahwa ada perbedaan antara disfungsi seksual wanita pasca persalinan dengan episiotomi mediolateral dengan seksio sesarea dengan dengan nilai t-hitung $>$ t-tabel, baik pada hasrat, rangsangan, lubrikasi, orgasme, kepuasan dan nyeri dimana menurut hasil penelitian terdapat perbedaan yang signifikan antara persalinan normal dengan episiotomi dan persalinan dengan sectio cesaria. Hasil penelitian ini sudah sesuai pada teori yang dijelaskan oleh Safarinejad et al., (2012). Perempuan yang melahirkan dengan seksio sesar elektif mempunyai skor FSFI paling tinggi dibanding wanita yang melahirkan pervaginam baik dengan spontan, episiotomi maupun dengan bantuan alat.

Meskipun penelitian tersebut unggul dalam beberapa aspek, termasuk meneliti tingkat kepuasan seksual dari pasangannya, tapi yang diteliti hanya pada perempuan primipara.Jadi untuk perempuan multipara belum diketahui tingkat disfungsi seksualnya. Disamping itu, dengan tindakan sesar tentunya akan meningkatkan resiko operasi pada kehamilan selanjutnya, serta meningkatkan resiko terjadinya perdarahan, infeksi, resiko anestesi, deep vein thrombosis, emboli pulmonal, wound dehisence, cidera blader dan usus serta resiko laserasi janin. Jadi evidence base yang mendukung bahwa seksio sesar lebih baik menjaga perempuan dari PPFSD (Post Partum Female Sexual Dysfunction) dibandingkan persalinan pervaginam belumlah cukup.

\section{KESIMPULAN}

Hasil penelitian ini menunjukkan ada perbedaan antara disfungsi seksual perempuan pasca persalinan dengan episiotomi mediolateral dengan seksio sesarea, hal ini dipastikan dengan nilai $t_{\text {hitung }}$ $>\mathrm{t}_{\text {tabel }}$.

\section{SARAN}

Dari hasil penelitian yang dilakukan, maka ada beberapa saran yaitu sebagai berikut:

1. Bagi Responden

Dengan adanya penelitian ini diharapkan responden memahami salah satu permasalahan yang muncul dari persalinan degan sectio cesaria sehingga persalinan dengan cara sectio cesaria jangan dilakuakn hanya berdasarkan keinginan tapi didasari karena indikasi.

2. Bagi Institusi Pendidikan

Diharapkan agar penelitian ini dapat dijadikan sebagai bahan panduan bagi peneliti selanjutnya untuk menambah referensi dan pengetahuan dan wawasan peneliti selanjutnya. 
3. Bagi Peneliti

Dapat digunakan sebagai bahan peningkatan ilmu pengetahuan serta dapat menyampaikan hasil penelitian ini kepada masyarakat.

\section{REFERENSI}

Alexander, et al. (2006). Praktik Kebidanan Riset dan Isu. Jakarta: EGC.

Breslin, E.T., \& Lucas, V. . (2003). Women's Health Nursing toward Evidence Based Practice. Missouri: Elsevier Science.

Buhling, KJ., Schmidt, S., Robinson, JN.,
Klapp, C., Siebert, G., Dudenhausen, J. (2006). Rate of Dyspareunia After Delivery In Primiparae According To Mode Of Delivery. Eur J Obstet Gynecol Reprod Biol, 124(1), 42-6.

Safarinejad, M. R, et al. (2012). Sexual Function of Primiparous Women after Elective Cesarean Section and Normal Vaginal Delivery. Urology Journal, 9(2), 498-503.

Trutnovsky, G, et al. (2006). Women's Perception of Sexuality During Pregnancy and After Birth. Australia and New Zealand Journal of Obstetrics and Gynaecology, 46, 282-287. 